Original Research Article

\title{
Prescribing patterns of gastrointestinal drugs in private clinics in Benghazi-Libya
}

\author{
Nouh M. H. Aljarari ${ }^{1}$, Suleiman I. Sharif ${ }^{2}$, Abdulrahman K. Jaber ${ }^{1}$, Abdelhadi S. Garini ${ }^{1}$, \\ Awad S. Awad ${ }^{1}$, Faraj A. Hamed ${ }^{1}$
}

${ }^{1}$ Department of Pharmacology, Benghazi University, BenghaziLibya

${ }^{2}$ Department of Pharmacy

Practice and

Pharmacotherapeutics, University of Sharjah, United Arab Emirates

Received: 18 October 2016 Accepted: 17 November 2016

\section{*Correspondence to:}

Dr. Suleiman Ibrahim El- Sharif, Email: sharifsi@sharjah.ac.ae

Copyright: (C) the author(s), publisher and licensee Medip Academy. This is an openaccess article distributed under the terms of the Creative Commons Attribution NonCommercial License, which permits unrestricted noncommercial use, distribution, and reproduction in any medium, provided the original work is properly cited.

\begin{abstract}
Background: Prescription analysis can pinpoint areas of improvement in encounters issued by prescribing physicians. The present study was carried out to analyze prescribing trends for outpatients among consultants in the city of Benghazi-Libya.

Methods: A total of 4000 prescriptions were collected from private pharmacies around the city of Benghazi, Libya. Indicators addressed included the patient's name, age, sex, and address, and the physician's name, address, and signature. The percentage of prescriptions lacking this information was calculated. Drugs prescribed by dosage, duration of treatment were also considered. The study focused on the commonly prescribed classes of gastrointestinal drugs and the most frequently prescribed drug of each common class. No attempt was made to evaluate the incidence of various gastrointestinal disorders. Results are expressed as frequency and percentage of prescribed medicines.

Results: Information present in prescriptions and pertaining to the patient were name $(2972,74.3 \%)$, age $(468,11.7 \%)$, date of visit $(107,2.7 \%)$ while those for prescriber were name $(1902,47.6 \%)$ and signature $(3612,90.3 \%)$. None of the prescriptions contained sex of patient, his/her address, or registration number of the prescriber. All prescribed drugs were in brand names. Polypharmacy was not evident as all prescriptions contained 1-2 drugs.

The number of prescriptions with a gastrointestinal drug(s) counted to 421 $(10.5 \%)$ out of the total 4000 prescriptions. The most commonly prescribed classes of gastrointestinal drugs include in order, anti-hyperacidity, antiemetics, anti-spasmodic, laxatives and anti-diarrheal with the most frequently prescribed drug of each therapeutic class being omeprazole (67, 48.9\%), metoclopramide $(57,57 \%)$, hyoscine-N-butyl bromide $(42,55.3 \%)$, bisacodyl $(44,59.5 \%)$ and loperamide $(30,88.3 \%)$ respectively.

Conclusions: The results of the present study indicate the need to improve prescribing among physicians, a task that can be achieved through inclusion of related topics such as prescription writing and rational drug use in undergraduate curricula and continuing medical educational programs.
\end{abstract}

Keywords: Drug use indicators, Gastro-intestinal drugs, Prescription analysis

\section{INTRODUCTION}

Inappropriate use of medications in healthcare facilities is a common problem not only in developing but also in developed countries. ${ }^{1-4}$ Irrational prescribing can lead to serious hazards including, but not limited to, over-or under-treatment, adverse effects, drug interactions, emergence of bacterial resistance and exhaustion of the limited budget assigned for drugs particularly in poor countries. ${ }^{1}$ Among the easiest ways to examine an aspect of drug misuse is prescription analysis. Such investigation examines the patterns of drug prescribing. ${ }^{5}$ In Libya; all residents of the country enjoy free health care which is provided through primary health care centers. Patients gain access to secondary and tertiary care through referral from primary care centers. However, patients can seek medical services and consultation in private hospitals and clinics. A plethora of studies addressed rational drug prescribing. ${ }^{6}$ Prescription analysis using the core drug use indicators set by the World Health Organization (WHO) are routinely employed to 
indicate the trends of prescribing by physicians. ${ }^{7,8}$ It is important to closely monitor the prescriptions issued by consultants in private practice. We have earlier pointed out areas for improvement in prescription writing. ${ }^{9}$

The present study analysed prescriptions issued by consultants in private practice in the city of Benghazi, Libya. The objective was to investigate the pattern of prescribing drugs for gastrointestinal disorders. Such analysis of prescriptions can pinpoint deficiencies, if any, and the results of such studies can be utilized as an effective intervention by feeding it back to and discussing it with the prescribers and health authorities to promote rational drug prescribing.

\section{METHODS}

A perspective study was carried out using a total of 4000 prescriptions those were collected from private pharmacies around the city of Benghazi, Libya. Indicators addressed included the patient's name, age, sex, and address, and the physician's name, address, and signature. The percentage of prescriptions lacking this information was calculated. Drugs prescribed by dosage, duration of treatment were also considered. The study was focused on the commonly prescribed classes of gastrointestinal drugs and the most frequently prescribed drug of each common class. We concentrated our analysis on antacids, antispasmodics, laxatives, antidiarrheal and antiemetic drugs. No attempt was made to evaluate the incidence of various gastrointestinal disorders. Results are expressed as frequency and percentage of the prescribed medicines.

\section{RESULTS}

Information present in prescriptions and pertaining to the patient were name $(2972,74.3 \%)$, age $(468,11.7 \%)$, date of visit $(107,2.7 \%)$ while those for prescriber were name $(1902,47.6 \%)$ and signature $(3612,90.3 \%)$. None of the prescriptions contained sex of patient, his/her address, or license (registration number) of prescriber (Table 1). All prescribed drugs were in brand names. Polypharmacy was not evident as all prescriptions contained 1-2 drugs.

Table 1: Information present in prescriptions issued to outpatients.

\begin{tabular}{|lll|}
\hline $\begin{array}{l}\text { Present } \\
\text { Information }\end{array}$ & $\begin{array}{l}\text { Number of } \\
\text { prescription }(\mathbf{N}=4000)\end{array}$ & $\%$ \\
\hline Patient name & 2972 & 74.3 \\
\hline Patient age & 468 & 11.7 \\
\hline Date of visit & 107 & 2.7 \\
\hline Physician name & 1902 & 47.6 \\
\hline Physician signature & 3612 & 90.3 \\
\hline
\end{tabular}

The number of prescriptions with a gastrointestinal drug(s) counted to $421(10.5 \%)$ out of the total 4000 prescriptions. Table 2 shows the most commonly prescribed classes of gastrointestinal drugs while Table 3 exhibits the most commonly prescribed drug of each therapeutic class of gastrointestinal medications. Encounters with anti-hyperacidity medications constituted $137(32.5 \%)$ of the total gastrointestinal prescriptions. Omeprazole 20mg $(39,28.5 \%)$ and $40 \mathrm{mg}$ $(28,20.4 \%)$ was the most frequently prescribed drug, followed by esomeprazole $20 \mathrm{mg}(24,17.5 \%)$ and $40 \mathrm{mg}$ $(26,19 \%)$ and ranitidine $150 \mathrm{mg}(20,14.6 \%)$.

Table 2: Frequently prescribed therapeutic classes of gastrointestinal drugs.

\begin{tabular}{|lll|}
\hline Therapeutic class & $\begin{array}{l}\text { Number of } \\
\text { prescription }(\mathbf{N}=421)\end{array}$ & $\%$ \\
\hline Anti-hyperacidity & 137 & 32.5 \\
\hline Laxatives & 74 & 17.6 \\
\hline Anti-spasmodics & 76 & 18.1 \\
\hline Anti-emetics & 100 & 23.7 \\
\hline Anti-diarrheal & 34 & 8.1 \\
\hline
\end{tabular}

Antispasmodics were prescribed in 76 (18.1\%) encounters with hyoscine-N-butyl-bromide being the most frequently prescribed $(42,55.3 \%)$ antispasmodic and chlordiazepoxide came second $(34,44.7)$. Laxatives were prescribed in $74(17.6 \%)$ of the total number of prescriptions studied with bisacodyl being the most frequently $(44,59.5 \%)$ and seconded by lactulose in 30 $(40.5 \%)$ of encounters.

Table 3: The most commonly prescribed drugs of each therapeutic class.

\begin{tabular}{|lll|}
\hline $\begin{array}{l}\text { Therapeutic class (N) / } \\
\text { Drugs }\end{array}$ & $\begin{array}{l}\text { Number of } \\
\text { prescription }\end{array}$ & $\%$ \\
\hline Anti-hyperacidity (137) & \multicolumn{2}{l|}{} \\
\hline Omeprazole & 67 & 48.9 \\
\hline Esmoprazole & 50 & 36.5 \\
\hline Ranitidine & 20 & 14.6 \\
\hline Laxatives (74) & 44 & 59.4 \\
\hline Biscodyl & 30 & 40.5 \\
\hline Lactulose & & \\
\hline Antispasmodics (76) & 42 & 55.3 \\
\hline Hyoscine-N-butyl bromide & 34 & 44.7 \\
\hline Chlordiazepoxide & & 57 \\
\hline Antiemetics (100) & 57 & 43 \\
\hline Metoclopramide & 43 & 88.2 \\
\hline Domperidone & & 11.7 \\
\hline Antidiarrheal (34) & 30 & \\
\hline Loperamide & 4 & \\
\hline Pectin and kaplin &
\end{tabular}

Whereas antidiarrheal drugs comprised only $34(8.1 \%)$ of gastrointestinal encounters with loperamide $(30,88.2 \%)$ being the most commonly prescribed. Prescriptions with an antiemetic constituted $100 \quad(23.7 \%)$ with metoclopramide being the most commonly $(57,57 \%)$ prescribed drug followed by domperidone $(43,43 \%)$. 


\section{DISCUSSION}

Results of the present study revealed that drug use pattern in private practice are not in line with the WHO drug use guidelines. Information missing with regard to patient sex may lead to serious adverse effects particularly in the pregnant or lactating female. It must be noted that names may not always reflect the sex of the patient. In addition address of patient is again essential for easy contact in case of erroneous prescribing or dispensing. Information regarding both the patient and the prescriber were missing in most of the prescription. This is irresponsible prescribing behaviour particularly in the light of the fact that a prescription is considered a legal document that can be used in court. Such an issue of using a prescription for or against the prescriber or dispenser may arise in case of any serious health hazard.

In the present study, none of the drugs prescribed were generics. Considering the fact that in this study, the drugs subjected to analysis were entirely for gastrointestinal disorders, it seems inappropriate to prescribe only brands that may be costly to patients while a cheaper counterpart generic could have been prescribed. However, in our recent study in United Arab Emirates (UAE) we surprisingly found that generics were prescribed more by general practitioners $(10 \%)$ than by consultants $(5 \%) .{ }^{5} \mathrm{It}$ is also worth noting that prescribing generics has long been recognized to reduce cost and rationalize drug use. ${ }^{10}$

In the present study, prescribing antispasmodic drugs came third among the most frequently prescribed therapeutic classes with hyoscine-N-butyl bromide being the most commonly prescribed drug of the class. This is reminiscent to the results reported for studies in UAE. ${ }^{5}$ In general; prescribing drugs for gastrointestinal disorders in Benghazi does not seem to follow proper guidelines. Among the prescribed gastrointestinal drugs, those for hyperacidity were the most commonly $(137,32.5 \%$ ) prescribed with the proton pump inhibitor omeprazole being the most frequently $(48.9 \%)$ indicated of this class. Esmoprazole came second and ranitidine third. None of the prescriptions indicated a well diagnosed peptic ulcer or gastro-esophageal reflex disorder and none of the encounters was for a simple antacid. The possibility that some patients may have suffered ulcers cannot be completely eliminated but since no proper steps have been taken to adequately diagnose their presence, it does not seem wise to jump immediately for proton pump inhibitors. Moreover, a responsible management of a well-established ulcer may better be achieved by the use of triple therapy including the addition of antibiotics, particularly in the light of the fact that the majority of ulcers are due to $H$. Pylori infection. The class of antiemetic drugs came Second $(100,23.7 \%)$ with metoclopramide first $(57,57 \%)$ and domperidone second $(43,43 \%)$. As no other antiemetic drugs were used, one may assume that these particular prokinetic were prescribed to treat pregnancy sickness. However, no indication was made in any of the encounters to a patient being pregnant. This further enhances the need for an ideal prescription writing practice that ensures the inclusion of all important information such as sex, status of patient and brief history of the condition.

Antispasmodics were the third most commonly (18.1\%) prescribed with hyoscine-N-butyl bromide being the first and chlordiazepoxide second most commonly prescribed drugs of the class.

Laxative came fourth being prescribed in 74 (17.6\%) of encounters for gastrointestinal drugs with bisacodyl being the most frequently prescribed drug. On the other hand, only $34(8.1 \%)$ encounters were for drugs to treat diarrhea. Loperamide was the most frequently (30, $88.2 \%$ ) prescribed antidiarrheal medication. Strangely none of the prescriptions was for rehydration salts. Based on the previous results, we suggest that there is a need to promote the responsible prescribing among physicians and encourage generic prescribing.

\section{CONCLUSION}

The results of the present study indicate the need to improve prescribing among physicians, a task that can be achieved through inclusion of related topics such as prescription writing and rational drug use in undergraduate curricula and continuing medical educational programs.

\section{Funding: No funding sources}

Conflict of interest: None declared

Ethical approval: The study was approved by the Institutional Ethics Committee

\section{REFERENCES}

1. Sharif SI, Al-Shaqra M, Hajjar H, Shamout A, Wess L. Patterns of Drug Prescribing in a Hospital in Dubai, United Arab Emirates. Libyan Journal of Medicine. 2008;3:10-2. Available at: http://dx.doi.org/10.4176/070928

2. Irshaid YM, Al Homrany M, Hamdi AA, AdjeponYamoah KK, Mahfouz AA. Compliance with good practice in prescription writing at outpatient clinic in Saudi Arabia. Eastern Mediterranean Health Journal. 2005;11:922-8.

3. Meyer TA. Improving the Quality of the OrderWriting Process for Inpatient Orders and Outpatient Prescriptions. Am. J. Health-System Pharmacy. 2000;57:S18-2.

4. Montastruc F, Gardette V, Cantet C, Piau A, Lapeyre-Mestre M, Vellas B, et al. Potentially inappropriate medication use among patients with Alzheimer disease in the REAL.FR Cohort: Be aware of atropinic and benzodiazepine drugs! Eur. J. Clin. Pharmacol. 2013;69:1589-97.

5. Sharif SI, Fazli H, Tajrobehkar Y, Namvar Z, Bugaighis LMT. Drug Prescribing Trends among consultants and general practitioners in Sharjah- 
UAE. Pharmacology and Pharmacy. 2015;6:374-9. Available http://dx.doi.org/10.4236/pp.2015.68038

6. Karande S, Sankhe P, Kulkarni M. Patterns of prescription and drug dispensing. Ind $\mathrm{J}$ Paediat. 2005;72(2):117-21.

7. Quick JD, Hogerzeil HV, Velasquez G, Rago L. Twenty-five years of essential medicines. Bull WHO. 2002;80:913-4. International Network for Rational Use of drugs and World Health Organization. How to investigate drug use in health facilities: selected drug use indicators. EDM Research Series No. 7[WHO/DAP/93.1]. Geneva: World Health Organization. 1993. (Accessed, 10/10/2016)
8. Anonymus. Pharmacist, GP blamed for coma. The Guardian. 1988:17 March.

9. Sharif SI, Alabdouli AH, Sharif RS. Drug Prescribing trends in a general hospital in Sharjah, United Arab Emirates. Am. J. Pharmacol. Sci. 2013;1(1):6-9.

10. Quick JD, Hogerzeil HV, Velasquez G, Rago L, Twenty-five years of essential medicines. Bull WHO. 2002;80(11):913-14.

Cite this article as: Aljarari NMH, Sharif SI, Jaber AK, Garini AS, Awad AS, Hamed FA. Prescribing patterns of gastrointestinal drugs in private clinics in Benghazi-Libya. Int J Basic Clin Pharmacol 2017;6:113-6. 